\title{
Ecological and geochemical heterogeneity and structural organization of the modern noosphere
}

\author{
DR. ELENA M. KOROBOVA, PHD, DR. SCI. ${ }^{1}$ AND \\ SERGEY ROMANOV ${ }^{2}$
}

${ }^{1}$ Vernadsky Institute of Geochemistry and Analytical Chemistry, Russian Academy of Sciences

${ }^{2}$ State Unitary Enterprise Geoinformation systems, National

Belarus Ac. of Sci.

Presenting Author: helene_k@mail.ru

In the course of evolution, each natural species has occupied its own special geochemical niche with an optimal complex of geochemical conditions for it. Expanding beyond natural boundaries, humans started changing the biosphere in their interests, unwittingly transforming it to new state of noosphere and creating the prerequisites for the occurrence of not only endemic, but also somatic diseases caused by both a deficiency and an excess of chemical elements among humans and domestic animals. Based on these premises, we consider the structural organization of the modern noosphere as a complex of biogeochemical provinces with different levels of ecological and geochemical comfort, both natural and technogenic in origin. The natural geochemical heterogeneity of the noosphere has an explicit fractal organization: at the zonal level is due to climatic differences, at the regional level it is determined by geological history, and at the local level - by the specifics of the lateral redistribution of elements in an elementary landscape geochemical system. Technogenic heterogeneity is caused by a single or long-term supply of material, as a rule, from point sources. Thus, the modern noosphere can be considered as an integral, vertically and laterally stratified planetary envelope, organized in the form of a two-layer object, inside which a relatively thin layer of anthropogenic matter entering the environment in a specific way and in a specific form is superimposed on the primary biosphere background. Areas with combined geochemical conditions can be easily reproduced by the interference of the two above-mentioned layers having different spatial structures. By knowing the optimal content of biologically significant elements in the environment, it is possible to assess the risk of diseases as a function of the difference between the observed concentration of elements and the optimal one typical for any natural systematic group of organisms, including humans. The resulting risk map will identify areas requiring priority monitoring, as well as areas most suitable for living or housing medical and recreational facilities. It is important to note that deductive approach allows solving a significant class of environmental problems.

The study is partly supported by RFBR and BRFBR, project No. 20-55-00012. 